\title{
Microwaves and Radiowaves: In Food Processing and Preservation
}

\author{
Kanchan Bhatt*, Devina Vaidya, Manisha Kaushal, Anil Gupta, Pooja Soni, \\ Priyana Arya, Anjali Gautam and Chetna Sharma
}

Dr. Yaswant Singh Parmar University of Horticulture and Forestry, Nauni, Solan (HP), India

*Corresponding author

\section{A B S T R A C T}

\begin{tabular}{|l|}
\hline Ke y w o r d s \\
Drying, \\
Electromagnetic \\
radiations, \\
Microwaves, \\
Radiowaves, \\
Preservation \\
\hline Article Info \\
\hline $\begin{array}{l}\text { Accepted: } \\
\text { 04 August 2020 } \\
\text { Available Online: } \\
\text { 10 September } 2020\end{array}$ \\
\hline
\end{tabular}

Microwaves and Radiowaves are the non ionizing electromagnetic radiations ranging between $300 \mathrm{MHz}$ to $300 \mathrm{GHz}$ and $300 \mathrm{KHz}$ to $300 \mathrm{MHz}$ respectively. They are used in various fields, however, they are gaining marked popularity in food technology nowadays. This paper reviewed the history, basic principles, advantages, disadvantages, uses and applications of microwaves and radiowaves in the field of food preservation and processing as these technologies have increased the amount of nutrient retention in the treated food with increase in shelf life of food along with less use of preservatives.

\section{Introduction}

Electromagnetic spectrum consists of ionizing and non-ionizing radiations (Gava, 1984). Gamma rays and $X$ rays falls in ionizing part of it, however, UV rays, Visible light, Infra, Micro and Radio waves are the part of nonionizing radiations. Ionizing Radiations with high frequency (higher than $1014 \mathrm{~Hz}$ ) have capability to ionize atomic bonds in cell molecules and their excessive exposure to this effect can lead to hazardous conditions such as damage to living cells and also DNA chain. On the contrary, non-ionizing electromagnetic radiations have not enough energy to separate atomic bonds and are ranged from $1 \mathrm{~Hz}$ to $1014 \mathrm{~Hz}$. However, these radiations cause thermal effects on human body depending on distance, frequency power and time. Electromagnetic radiations are used in many fields like Energy Transmission Lines (ETL) and transformer stations, Electric trains, Cathode Ray Tube (CRT) displays used in TVs and computers, Induction furnaces and welding machines used in the industry, all kinds of electrical household appliances (iron, microwave ovens, cordless phones, electric blankets, refrigerators, etc.) used in our homes, Various RF systems operating in industry, Radar systems (continuous and 
pulsed), Satellite communication systems, Personnel communication systems (Cordless, telephone, Wi-Fi, Bluetooth, etc. (Ozkaya et al., 2018). Recently, we have seen the usage of electromagnetic waves in the field of food processing and preservation. Lately, the microwave or radio wave region of the electromagnetic spectrum has been emerged potentially for possible use in food processing and preservation with successful results in microbial inactivation. Here we will discuss about these two technologies and their contributions to food.

\section{Microwaves}

Microwaves are nonionizing radiations that induces molecular motion by ion migration and dipole rotation but does not alter the composition of the molecules. Microwave energy is a part of electromagnetic spectrum, and is defined by wavelength range between $1 \mathrm{~mm}$ to $1 \mathrm{~m}$ and frequency range between 300 $\mathrm{MHz}$ and $300 \mathrm{GHz}$. These are usually used for the industrial processing of foods being between 915 and $2450 \mathrm{MHz}$ and $2450 \mathrm{MHz}$ for domestic use.

\section{Brief history of microwaves}

Microwaves were the result of desired energy transfer rate enhancement which led to an increased frequency. During 1946, a self taught engineer Dr. Percy Spencer was testing magnetron (a new vacuum tube) and while working on it surprisingly the candy bar in his pocket melted. The occurrence of this incident lead to the implementation of microwave energy into the food industry (Fito et al., 2005). However, the first patent was issued in 1952 (Spencer, 1952) describing an industrial conveyor belt microwave system and its first application started 10 years later. Whereas, during the Second World War, microwave technology was principally used for communication, with the development of radar. This led to the development of high power microwave sources. According to Decareau, 1985 the first major applications were finish drying of potato chips, precooking of poultry and bacon, tempering of frozen food and drying of pasta.

\section{Principle}

A soon as microwave energy is absorbed, polar molecules such as water molecules inside the food will rotate according to the alternating electromagnetic field. The water molecule is a "dipole" itself with one positively charged end and one negatively charged end. Thus, water molecule acts like magnet, and these dipoles have similar orientation when they are subject to electromagnetic field. The rotation of these water molecules would generate heat for cooking (Ohlsson, 1993). Thus, the composition of a food will affect its heating inside microwave oven. Due to the dipolar interaction food with higher moisture content will be heated up faster. In nonconductors, microwave heating refers to dielectric heating at a selected frequency bands due to polarization. However, coupling of electrical energy from an electromagnetic field in a microwave cavity with the food results in its heating as well as its subsequent dissipation within food product. This in turn results in a sharp increase in temperature within the product. MW energy is transferred at a molecular level through interaction of molecules with the electromagnetic field, particularly, through molecular friction which results from dipole rotation of polar solvents and from the conductive migration of dissolved ions. Second major mechanism of heating with microwaves is through the polarization of ions which results in the backward and forward movement of the ionic molecules trying to align themselves with the oscillating electric field (Oliveira and Franca, 2002). 


\section{How a microwave oven works}

The process starts when electrical energy, in the form of low-voltage alternating current and high-voltage direct current, is converted into direct current. Magnetron (heart of microwave) after using this direct current, generates microwaves with a frequency of 2450 megacyles per second $(2.45 \mathrm{GHz})$. The microwaves are controlled by an antenna at the top of the magnetron into a waveguide. The waveguide streamlines microwaves to a fan like device called a stirrer which disperses them inside the oven cavity. Later on the microwaves are reflected by the metal walls of the oven's interior and are absorbed by molecules in the food. Because each wave is made up of a positive and negative component, the molecules in the food are pushed back and forth at twice the rate of the microwave frequency (4.9 billion times a second).

\section{Working of magnetron}

The magnetron is also known as heart of microwave oven which converts electrical energy to microwave radiation. Magnetron uses low-voltage alternating current and highvoltage direct current.

Later on, a transformer changes the incoming voltage to the required levels and a capacitor, in combination with a diode, filters out the high voltage and converts it to direct current. Electrons are emitted from a central terminal called a cathode, inside the magnetron and are attracted by positively charged anode surrounding the cathode.

Rather a straight line movement, permanent magnets force the electrons to take a circular path. As soon as, they pass by resonating cavities, there is generation of continuous pulsating magnetic field, or electromagnetic radiation.

\section{Factors affecting microwave heating}

\section{Frequency}

There are two frequencies allocated for microwave heating (915 and $2450 \mathrm{MHz}$ ) for the application of food having frequencies of 0.328 and $0.122 \mathrm{~m}$. These wavelengths are significant as most interactions between the energy and materials take place in that region and generate immediate heat due to molecular friction.

\section{Dielectric properties}

The electrical properties of microwave and radiofrequency heating are classified as dielectric properties, which provide details, how food materials interact with electromagnetic energy. Initially when we preheat microwave it reaches higher temperature than the preset temperature, to compensate the effect of higher initial temperature, the power of MW oven should be reduced or a higher sample mass should be used or the product should be heated for a shorter duration (Mudgett, 1989).

\section{Geometry and location of foods}

The shape of the food affects the depth of microwave penetration, heating rate and uniformity. Due to the difference in product thickness, irregular-shaped products are subjected to non uniform heating. The closer the size and wavelength ratio, the higher will be the center temperature.

Smaller particulates require less heat than larger ones. Moreover, regularity in the shape increases the uniformity of heat distribution within the product. A food of a spherical or cylindrical shape heats more evenly than a square. A higher surface-to-volume ratio enhances the heating rate. 


\section{Thermal properties}

Thermal conductivity of food plays a pivot role in microwave heating. During microwave heating foods with higher thermal conductivity dissipate heat faster than the ones with lower conductivity. Thus, food having high thermal conductivity will take lesser time to attain uniform temperature during holding (Ahmed and Ramaswamy, 2005).

\section{Moisture content}

The moisture content affects the dielectric properties of the food product and penetration depth of the microwaves. Foods with high moisture content shows low microwave penetration depth, and thus results in, uneven heating rate unlike, low-moisture foods which will have more uniform heating rate due to the deeper microwave penetration. During microwave heating the initial moisture content of the product and the rate of moisture evaporation plays an important role (Mudgett, 1989).

\section{Mass}

There is direct relationship between the mass and the amount of absorbed microwave power, which should be applied in order to achieve the desired heating. For a smaller mass generally we use batch oven, however, for large capacity equipment conveyors are used. These equipments provide great heating uniformity by movement of product through the microwave field.

For its efficient operation each microwave oven has a critical (minimum) sample mass which is usually around $250 \mathrm{ml}$ water load in a $1 \mathrm{~kW}$ oven. No, significant amount of microwave power is absorbed into the product below this level, and at very low loads they may damage the magnetron.

\section{Temperature}

Depending upon the material, dielectric properties may vary with temperature. Both moisture content and temperature can change during heating and therefore, show combined effect on the dielectric constant, dielectric loss factor, loss tangent, and subsequently on the heating behavior (Khattarpaul, 2005).

\section{Advantages and disadvantages}

The very first advantage is that heat is generated in the product itself. Microwave penetrates inside the food materials resulting in entire internal cooking of whole volume of food rapidly and uniformly reducing the processing time and energy. This fast heat transfer in turn results in preservation of nutrients, vitamins contents, flavor, sensory characteristics, and color of food. Due to the elimination of the hot heat transfer surfaces minimum fouling depositions are found. Microwaves have high heating efficiency ( $80 \%$ or higher efficiency can be achieved). They have perfect geometry for clean-in-place (CIP) system. Microwaves are suitable for heat-sensitive, high-viscous, and multiphase fluid as well as low cost in system maintenance. One main advantage is that effect of small heat conductivities or heat transfer coefficients does not play such an important role. As a consequence, larger pieces can be heated in a shorter time and with a more even temperature distribution. These advantages often yield an increased production.

Microwaves need a lot of knowledge or experience to understand the moderate effects like uneven heating or the thermal runaway along with high input of engineering intelligence. Secondly, microwave heating in comparison with conventional heating needs electrical energy, which is its most expensive form. 


\section{Radiowaves}

\section{Introduction}

Radiofrequency (RF) heating can be defined as electromagnetic heating and other nonthermal methods that have the ability to provide high quality foods economically. Radiofrequency heating is a type of dielectric heating which uses radio waves as heating source. Radiowaves (RW) are the electromagnetic waves having frequency range between $300 \mathrm{KHz}$ to $300 \mathrm{MHz}$ and wavelength more than $10^{8} \mathrm{~nm}$ (Ryynanen, 1995). When food products are exposed to radio waves they gain heated due to ionic depolarization and dipole rotation. RF can be applied in all the fields of food industry such as pest control in agricultural field and thermal inactivation of pathogenic microbes in processed foods. Mainly, it is used in drying of baked goods like crackers, cookies, biscuits, pasta etc. (Orsat and Raghavan, 2005).

\section{History}

In 1895, RF heating was first used as a medical treatment method, however, according to Püschner, 1996 development of dielectric heating applications in food industry started in the radio frequency range in the 1930s. In food processing industry, it was used firstly for blanching followed by cooking and then dehydrating (Proctor and Goldblith. 1948; Moyer and Stotz, 1947). In the 1960s, there were attempts to use RF to the frozen foods. These researches led to successful commercial application of RF in thawing of fish blocks. Between 1960s and 1980s little research was reported from the university laboratories on radiofrequency heating of foods. Later in 1990s, with increase in power, commercially available electric property, temperature measurement devices, new findings were reported from laboratories of several universities (Mitcham et al., 2004; Monzon et al., 2004; Wang et al., 2002).

\section{Equipment}

The Radiofrequency heating system consists of two parts RF generator/ Triode valve for the radio waves generation and applicator which mainly consists of pair of electrodes for RF waves application to the food (Fig 2). Food product is placed between the two electrodes and heated without touching the material. Out of the two electrodes one works as a capacitor to store energy. These electrodes are used in three configurations, first one is through field configuration which is widely used for thick products and high voltage frequency is applied. Secondly, fringefield configuration is used for thin products and it consists of set of electrodes that are alternatively connected to RF generator. The third one is staggered through field configuration used for medium thick products (Marra et al., 2009).

\section{Principle and heating mechanism}

RF heating system consists of a RF generator which creates an alternating electric field between two electrodes and heat the material placed between the electrodes. Ionic depolarization and dipole rotation are the two phenomena responsible for heating. Alternating electric field causes polarization in molecules so that they will start continuously reorienting themselves to face opposite poles. Positive ions will be attracted to negative regions and negative ions will be moving to positive regions of electric field. With continuously changing polarity and high frequency heat energy is released throughout its mass as a result of friction due to rotational movement of molecules oscillating forward and backward. Polar molecules try to align themselves with changing polarity of electric field along with the movement of ions. 
Therefore, in the entire product wherever moisture is present oscillates and generates heat uniformly throughout the product. Radiations with lower frequencies predominantly have ionic polarization as heating mechanism while radiations with higher frequencies have both ionic polarization and dipole rotation as dominating heating medium (Tang et al., 2005).

\section{Advantages}

Radiofrequency heating has many advantages, firstly, dipole rotation and ionic polarization are methods used to generate simultaneous heat throughout the material resulting in faster process and reduction in the chances of overheating and browning. Secondly, it is a less time consuming rapid method over conventional heating (Jojo and Mahendran, 2013) and other benefits are ease of targeting the product, not the air surrounding it, tends to drive the moisture from inside out, and hence leveling the moisture, considerably decreasing the processing time, avoiding overheating, dehydration on the surface of the product and heating system can be turned on or off instantly along with temperature measurement systems (thermocouple). It has low maintenance cost as compared to other methods, greater penetrating depth than microwaves and high technology tools such as well design applicators, uniform heating pattern and higher energy efficiency makes this process more suitable for food industry.

\section{Disadvantages}

Radio frequency heating requires high initial capital cost and skilled labours for its handling. Proper shielding is also a major concern as this method uses electromagnetic waves as a source of heat (Ferdous et al., 2017). The major obstacle in RF technology is non uniform heating of food produce due to factors like dielectric properties, size, shape, position between the RF electrodes and the electrode configuration which affects temperature uniformity.

The major obstacle in RF technology is non uniform heating of food produce due to factors like dielectric properties, size, shape, position between the RF electrodes and the electrode configuration which affects temperature uniformity. Microwave penetrates inside the food materials resulting in entire internal cooking of whole volume of food rapidly and uniformly reducing the processing time and energy. This fast heat transfer in turn results in preservation of nutrients, vitamins contents, flavor, sensory characteristics, and color of food. Changes in sensory attributes and acceptability are minimized during processing as compared to radio and microwave processing.

\section{Application of microwave and radio wave}

\section{Application of microwave}

\section{Drying}

Application of Microwave energy in combination with convective air drying in three different methods, were explained by Andrés et al., (2004). At the beginning of the drying process, where the interior of the product is quickly heated to the evaporation temperature which inturn results in movement of large amount of vapor from the inner core of the sample towards the outer surface of the product and finally it is removed by the surrounding air. This increases drying rate throughout the process and leads to puffing of the sample which creates a porous structure which facilitates moisture flow to the surface. Next, the moisture near the surface of the product has been removed, while the inner core of the food particle remains moist. Thus, microwave energy can be applied when the drying rate begins to fall. The application of MW energy thus heats this trapped moisture to evaporation temperature and facilitates its 
movement to the outer layers of the sample. Finally, microwave energy can also be applied in the final stages of drying to remove bound water and to control the effects of product shrinkage, which can decrease drying rate over time. According to Prabhanjan et al., (1995) better rehydration characteristics may be expected in microwave dried products as the quick energy absorption by water molecules causes rapid evaporation of water, thus, results in an outward flux of rapidly escaping vapour. Besides, improving the rate of drying, this outward flux can prevent the shrinkage of tissue structure, which is common in most conventional air drying techniques. Recently, microwave drying has evolved as an alternate drying method for a wide range of food products such as fruits, vegetables, snack foods and dairy products. Food products like plain yogurt, cranberries, carrot slices, model fruit gels, skimmed milk, milk, casein powders, butter and fresh pasta and potato slices (Kim and Bhowmik, 1995; Yongsawatdigul and Gunasekaran, 1996a; Lin et al., 1998; Drouzas et al., 1999 Al-Duri and McIntyre, 1992; Bouraout et al., 1994) have been successfully dried by the microwave-vacuum application and/or by a combined microwave assisted-convection process. Another group of researchers proposed a two-stage drying process involving an initial forced air convective drying, followed by a microwave drying (Prabhanjan et al., 1995; Feng and Tang, 1980). It is however, reported that microwave application can improve product quality such as better aroma, faster and better rehydration, considerable savings in energy and less time consuming as compared with hot air drying alone. Finished Green tea has to go through number of processes such as overall finishing, air stream grading, stem separation, drying and roasting. Currently, new system uses a microwave oven for the drying processing order to reduce the water content of halffinished tea from $8-10 \%$ to $1-2 \%$. Later these dried tea leaves are sent into a rotary drum with a long-wave infra-red heater, installed below the microwave oven, where they are roasted into tasty, fragrant, finished tea.

\section{Sterilization and pasteurization}

Ohlsson (1987) reported that microwave sterilization $\left(128^{\circ} \mathrm{C}\right.$ and $3 \mathrm{~min}$ processing time) produced superior products as compared to conventional processes of canning $\left(120^{\circ} \mathrm{C}\right.$ retort temperature and $45 \mathrm{~min}$ processing time) and retorting foil pouches $\left(125^{\circ} \mathrm{C}\right.$ and 13 min cooking time). According to Tong et al., (1994) no significant change was observed in the texture of product or flavor loss when microwave heating at $915 \mathrm{MHz}$ was used to sterilize pouches containing cooked macaroni and cheese. Esteve et al., (1998) stated that microwave sterilization is a hightemperature-short-time (HTST) type process which not only used to inactivate spoilage microorganisms in foods but also to minimize the quality deterioration of foods

Continuous-flow microwave pasteurizer was developed for an experiment by Jaynes, (1975) using a Teflon tube $(12 \mathrm{~cm} / 0.635 \mathrm{~cm})$ placed across a $2450 \mathrm{MHz}$ microwave guide with a holding time of $15 \mathrm{~s}$.

However, the effectiveness of pasteurization was considered on the basis of inactivation of phosphatase enzyme, standard plate, and coliform counts. Villamiel et al., (1996) reported microwave pasteurization of milk which results in lower levels of denaturation of whey proteins in comparison to conventional thermal processes however denaturation of -lactoglobulin was almost equivalent in both processes. Helmar et al., (2007) studied the applications of microwave pasteurization and sterilization on cover prepacked food like yoghurt or pouch-packed meals as well as continuous pasteurization of fluids like milk. 
Fig.1 Structure of microwave heating device (Canadian Centre for Occupational Health \& Safety)

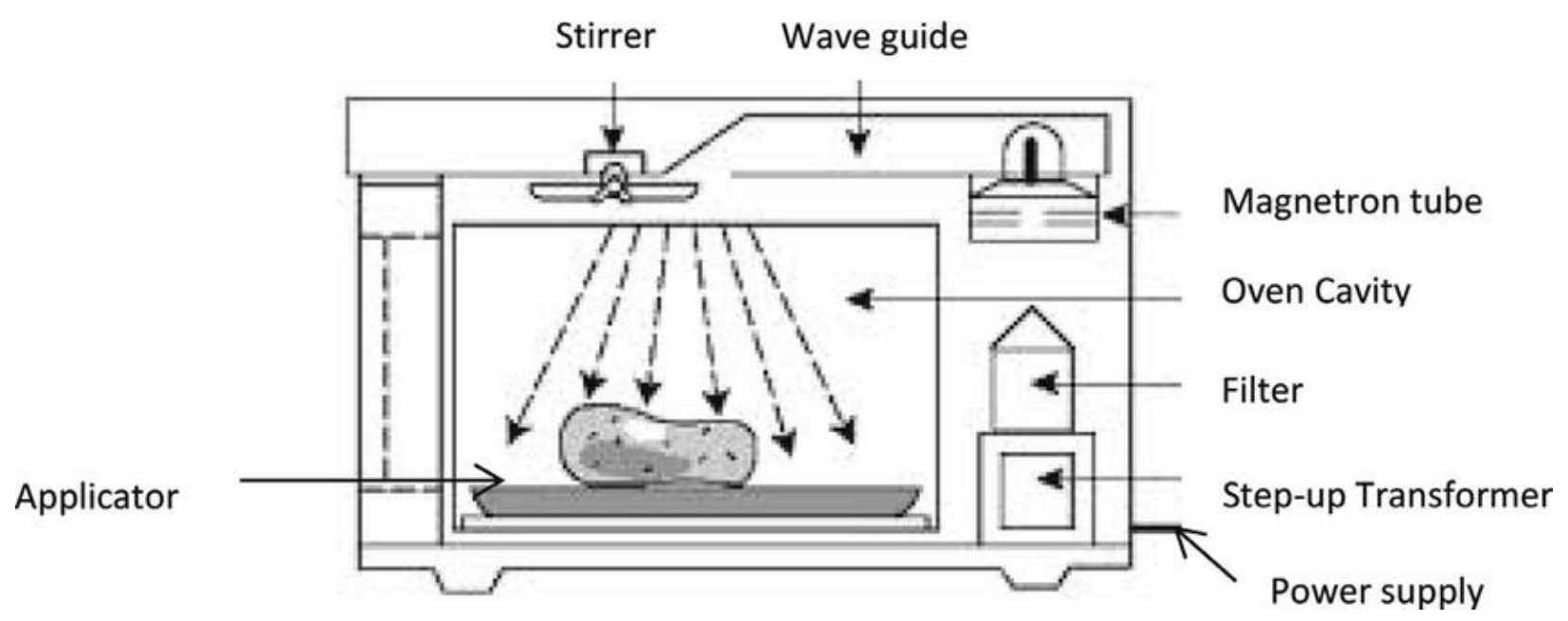

Fig.2 Schematic diagram of radio frequency treatment (Solar et al., 2005)

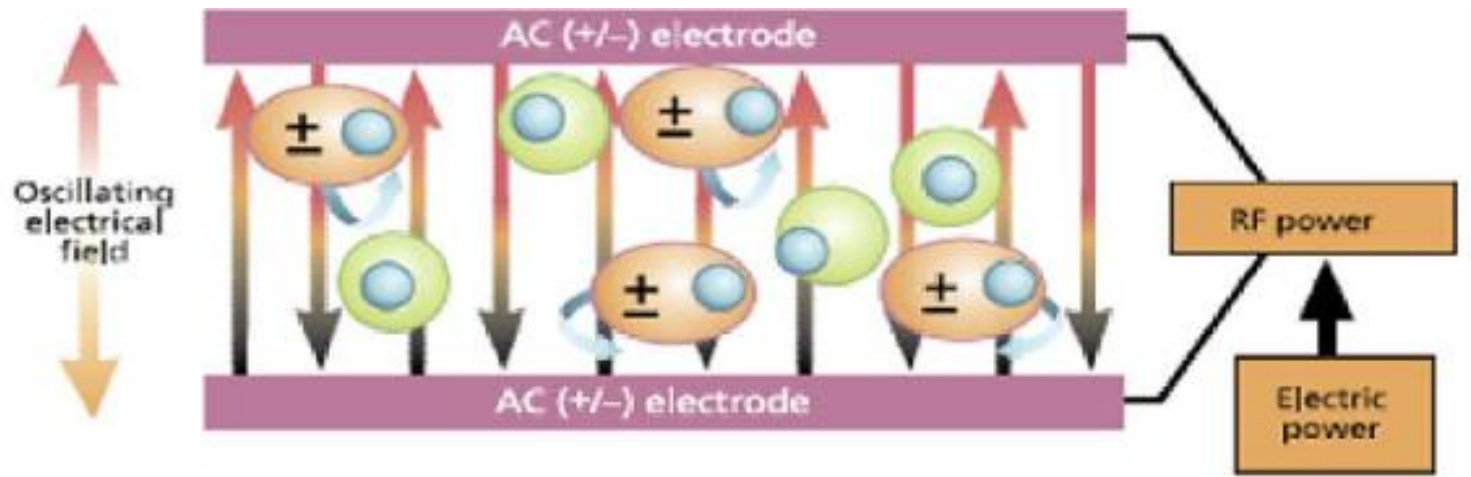

\section{Microwave blanching}

Proctor and Goldblith (1948) reported the first microwave blanching using $3000 \mathrm{MHz}$ for some green vegetables, and it was revealed that vegetables can retain maximum amounts of vitamin $\mathrm{C}$. However, many results indicate that microwave blanching was more efficient in retaining water-soluble vitamins in vegetables as compared to conventional blanching methods. Muftugil (1986) observed better retention of vitamin $\mathrm{C}$ in microwave blanched samples as compared to hot water blanched samples of green beans. Advantages of microwave blanching as compared with conventional heating methods include speed of operation, energy savings, precise process controls and faster start-up and shut-down times has been reported by Kidmose and Martens (1999). For retention of nutritional quality of food products, several researchers suggested the use of microwave heating as an alternative to conventional blanching method for food products (Giami, 1991; Ponne et al., 1994; Sánchez-Hernández et al., 1999 and Ramesh et al., 2002). According to Lin and Brewer (2005) for effective heat transfer in food microwave blanching requires little or no water thus it can reduce the amount of nutrients lost by leaching in comparison to hot water immersion. The study on microwave blanching of peanuts has been conducted by Schirack et al., (2007) and reported that microwave blanching was better than 
traditional blanching techniques in terms of energy and time savings. However, it was also observed that high temperature microwave blanching of peanuts resulted in the occurrence of stale/floral and ashy-off flavors. Patricia et al., (2011) studied a clear positive effect of microwave blanching on the nutritional quality of broccoli and reported that the amounts of protein, ashes, vitamin C, iron and phosphorus found in broccoli blanched by microwave were much more than the sample treated by hot water blanching as well as they were much closer to fresh broccoli. Minute difference in color, volatile aroma compounds, and sensory attributes between fresh dill and dried dill was observed by Straumite et al., (2012) which was hot water blanched at $90^{\circ} \mathrm{C}$ temperature for $30 \mathrm{~s}$ followed by microwave pretreatment at 900 $\mathrm{W}$ for $30 \mathrm{~s}$. Overall quality was good due to synergistic effect of hot water blanching assisted with microwave pretreatment.

\section{Application of radiowave frequency in food processing}

\section{Pest control}

Conventional fumigation agents such as methyl bromide infect fruits and nuts thus they are replaced by RF radiation. As per study the conducted by Tang et al., 2000 and Birla et al., 2008, intrinsic thermal mortality of insect pests showed the potential to develop high-temperature-short-time thermal treatments in order to control codling moth in fruits. A Lab-scale fruit-mover which is capable of continuously rotating the fresh fruit (with an orange and an apple as test samples) through a series of water jets in order to achieve uniform RF heating was developed by Birla et al., (2008) and found that apples with typical geometry (oval and dimples on ends) showed more temperature variation as compared to the almost spherical oranges. Monzon et al., (2007) studied the impact of RF heating to control Mexican fruit fly larvae on Fuyu persimmons fruit and observed that the treatments used at $(48-52$ ${ }^{\circ} \mathrm{C}$ ) followed by holding times of 0.5 to $18 \mathrm{~min}$ ) had no significant effect on firmness, soluble solids content, titratable acidity or product weight loss. An efficient RF treatment protocol has been developed for almonds for uniform heating and occurrence of RF in differential heating of insects.

\section{Meat processing}

The comparison of the rate of heating, timetemperature profiles and quality of three meat products (ground, comminuted and noncomminuted muscle) cooked in a water bath or by a $1.5 \mathrm{~kW}$ and $27.12 \mathrm{MHz}$ RF heater (a cylindrical chamber set between two electrodes wrapped around the RF applicator) was conducted by Laycock et al., (2003) and reported that the cooking time was reduced by up to $1 / 25$ and the surface of the RF cooked products became heated at a faster rate than the centre, with differences of 10-20 C. However, juice losses in the RF cooked food samples were less and thus were acceptable in terms of colour and water-holding capacity. Lagunas-Solar et al., (2005) reported that the Radio frequency process operated at $70-90^{\circ} \mathrm{C}$ range with high efficiency $(50 \%)$, compares well with the $10-15 \%$ efficiency for conventional surface heating methods as they are uniform and show deep penetration of RF waves which results in rapid and homogeneous heating as well as provide greater than $99.999 \%$ reduction in infection levels for Salmonella sp., and for Escherichia coli O157:H7 when compared to control. Wang et al., (2012) reported that the RF heating at $27 \mathrm{MHz}$ and application of an alternating current of $6 \mathrm{~kW}$ can be used for processing of pre-packaged heterogeneous foods (meat lasagna in large polymeric containers (295 x $253 \times 42 \mathrm{~mm}$ ) for retaining product quality as compared to conventional 
method of heating. RF cooking effects the quality, temperature distribution and heating rate of chicken breast meat at $27.12 \mathrm{MHz}$ until the center of the breasts reached to 74 ${ }^{\circ} \mathrm{C}$. After this heating method is compared to the conventional one it is explained that, the time to reach end point temperature in the RF oven was significantly less compared with water bath (conventional method), where yield, moisture content, $\mathrm{pH}$, expressible moisture, shear value of RF and water bath (WB) cooked chicken breast meat were statistically the same (Kirmaci et al., 2012).

\section{Drying and baking}

A simulation model for RF-assisted convective drying for the seed quality of broad bean was developed by Ptasznik et al., (1990). Drying of alfalfa using a combination of RF power at $27 \mathrm{MHz}$ with heated forced air has been reported by Murphy et al., (1992). Mermelstein, (1998) observed that RF drying provides uniformity in moisture content of final products and reduces the possibility of mould growth, which consequently increases the shelf-life. Later, Jumah (2005) prepared a theoretical analysis of simultaneous heat and mass transfer in the RF-assisted fluidized bed drying of corn particulates. This model worked efficiently as a tool for computeraided optimization of RF-enhanced fluidized bed drying processes. The main problem associated with post baking is surface cracking which occurs during traditional drying processes due to moisture gradients in the product. RF drying can solve this problem because of its uniform penetration minimizing moisture gradients. Not only this, RF is highly energy efficient for removing final moisture from dry baked products. Conventional baking is carried out in forced-air convection ovens where the heat is transferred to the surface of the dough by convection, conduction, and irradiation, and then from the surface toward the inside by heat conduction.
The dough has low heat conductivity thus, the traditional baking process is slow and can require as long as $30 \mathrm{~min}$. On the other hand, in RF processing of bread, dough pieces are placed inside pans made of heat-resistant, RF compatible, food-grade polymers and introduced into the RF baking oven with controlled-temperature air flow and exhaust fans in order to remove excess moisture released during the baking process. Total time for baking is reduced to $8-10 \mathrm{~min}$ for commercial bread loaves, and the bread develop a crust when it comes out of the RF oven (Awuah et al., 2014).

\section{Liquid foods}

In order to evaluate the effect of system parameters such that flow rate and RF power at $1.5 \mathrm{~kW}, 27.12 \mathrm{MHz}$. continuous heating of starch and guar solutions was investigated respectively by Awuah et al., (2002) and Piyasena and Dussault (2003), however, to find optimum conditions to inactivate surrogates of both Listeria and E. coli cells in milk under continuous laminar flow conditions, Awuah et al., (2005) used a $2 \mathrm{~kW}$, 27.12 MHz, RF applicator. The effect of RF treatment on microbial inactivation in orange and apple juices and in apple cider was studied by Geveke and Brunkhorst (2004, 2008) and by Geveke et al., (2007). Mainly they focused on microbial inactivation and quality of beverages processed using the system which provides a RF heating source of $15 \mathrm{kHz}$ to a maximum of $41 \mathrm{kHz}$ and varied with the product type and increasing the product temperature to maximum of $65^{\circ} \mathrm{C}$ at the outlet. Experimentally this method was effective as compared to traditional one. Along with this, maximum microbial inactivation the RF treated samples are found to be similar in its color and flavor property to the natural juices with negligible loss in ascorbic acid or enzymatic browning in RF treated juices. Inactivation of Bacillus subtilis 
spores in soybean milk by radio-frequency flash heating at $28 \mathrm{MHz}$ by heating up to $115^{\circ} \mathrm{C}$ for $0.4 \mathrm{sec}$ was studied by Uemura et al., (2011). They further stated that Fouling of the electrode surface by the protein from the soybean milk became a problem with high electric- field on continuous treatment, which was later corrected by covering electrode surface with a Teflon film.

It is concluded, nowadays, people are more health conscious, they want ready to eat food inclusive of all essential nutrients with less preservatives. Electromagnetic waves are very useful for the food industry and have made processing easy and effective as compared to conventional methods Radiowaves have more penetration as compared to microwaves whereas, both of them are less time consuming and highly efficient, on the other hand, effective learning is needed to handle them. Thus, we can conclude that thorough learning of each method and better understanding of operations can be helpful in achieving our goals in near future.

\section{References}

Ahmed, J., and Ramaswamy, H. 2014. Handbook of food preservation In: Rehman S (ed). Microwave Pasteurization and Sterilization of Foods. $2^{\text {nd }}$ edn. CRC, London .

Al-Duri, B., and McIntyre, S. 1992. Comparison of drying kinetics of foods using a fan-assisted convection oven, a microwave oven, and a combined microwave/convection oven. Journal of Food Engineering. 15: 139-155.

Awuah, G. B., H. S. Ramaswamy, and J. Tang. 2014. Radio Frequency Heating in Food Processing: Principles and Applications. Boca Raton: CRC Press.

Awuah, G.B., Ramaswamy, H.S., Economides, A., Mallikarjuanan, K., (2005). Inactivation of Escherichia coli K-12 and Listeria innocua in milk using radio frequency (RF) heating. Innovative Food Science and Emerging Technologies. 6 (4):396-402.

Awuah, G.B., Ramaswamy, H.S., Piyasena, P., (2002). Radio frequency (RF) heating of starch solutions under continuous flow conditions: effect of system and product parameters on temperature change across the applicator tube. Journal of Food Process Engineering, 25 (3):201223.

Birla, S.L., Wang, S. and Tang, J. 2008. Computer simulation of radio frequency heating of model fruit immersed in water. Journal of Food Engineering. 84:270-280.

Bouraout, M., Richard, P., and Durance, T. 1994. Microwave and convective drying of potato slices. Journal of Food Process Engineering. 17:353-363.

Canadian centre for occupational Health and safety. 2018. Microwave Ovens and their Hazards. Accessed on: 26/05/2020.

Decareau, R.V. Microwaves in the Food Processing Industry. 1985. Orlando, Academic.

Drouzas, A.E., Tsami, E. and Saravacos, G.D. 1999; Microwave/vacuum drying of model fruit gels. Journal of Food Engineering. 39(3):117-122.

Esteve MJ, Frigola A, Martorell L, Rodrigo C. 1998. Kinetics of ascorbic acid degradation in green asparagus during heat processing. J Food Prot. 61: 15181521

Feng., H. and Tang, J. 1998. Microwave finish drying of diced apples in a spouted bed. Journal of Food Science. 63, 679-683.

Ferdous, M.S., Koupaie, E.H., Eskicioglu, C. and Johnson, T. 2017. An experimental $13.56 \mathrm{MHz}$ radio frequency heating system for efficient thermal pretreatment of waste water sludge. Progress in Electromagnetics Research.79:83-101.

Fito, P., Chiralt, A. and Eugenia, M. 2005. Current state of microwave applications to food processing, In: Novel Food Processing Technologies (Ed by G.V. 
Barbosa-canovas, M.S. Tapia, M.P. Cano), Marecel Dekker, New York, CRC Pess. Pp. 525-537.

Gava, A. 1984. Princípios de Tecnologia de Alimentos. 1st ed. São Paulo: Nobel. p. 284

Geveke, D.J., Brunkhorst, C. 2004. "Inactivation of Escherichia coli in apple juice by radio frequency electric fields". Journal of Food Science. 69 (3):134- 138.

Geveke, D.J., Brunkhorst, C. 2008. Radio frequency electric fields inactivation of Escherichia coli in apple cider. Journal of Food Engineering. 85 (2): 215-221.

Geveke, D.J., Brunkhorst, C., Fan, X. 2007. Radio frequency electric fields processing of orange juice. Innovative Food Science and Emerging Technologies. 8 (4):549-554.

Giami, S.Y. 1991. Effect of pretreatments on the texture and ascorbic acid content of frozen plantain pulp (Musa paradisiaca). J Sci Food Agr. 55: 667-671.

Helmar, S. and Marc, R. 2007. The microwave processing of foods, Woodhead Publishing Limited and CRC Press, 20312.

Jaynes, H.O. 1975. Microwave pasteurization of milk. J. Milk Food Technol. 38, 3867, 1975.

Jojo, S. and Mahendran, R. 2013. Radio frequency heating and its application in food processing: a review. International Journal of Current Agricultural Research. 9:42-46.

Jumah, R. 2005. Modelling and simulation of continuous and intermittent radio frequency-assisted fluidized bed drying of grains. Food and Bioproducts Processing. 83:203-210.

Khattarpaul, N. 2005. Food processing and preservation In: Microwave application to food, Daya publishing house, Delhi. 110- 120 .

Kidmose, U. and Martens, H. J. 1999. Changes in texture, microstructure and nutritional quality of carrot slices during blanching and freezing'. J Sci Food Agric.
79:1747-1753.

Kim, S.S. and Bhowmik, S.R. 1995. Effective moisture diffusivity of plain yoghurt undergoing microwave vacuum drying. Journal of Food Engineering. 24:137138. P1614-4.

Kirmaci, B., Singh, R. K. 2012. Quality of Chicken Breast Meat Cooked in a Pilotscale Radio Frequency Oven. Innovative Food Sci. Emerging Technol. 14:77-84.

Lagunas-Solar, Manuel, C., Nolan, X. Z., Timothy, K. E., Tin, D. T., Cecilia, P., James. S.C., Wayne, L.S., Ricardo, L. 2005. Disinfection of fishmeal with radiofrequency heating for improved quality and energy efficiency". Journal of the Science of Food and Agriculture. 85: 2273-2280.

Laycock, L., Piyasena, P. and Mittal, G.S. 2003. Radio frequency cooking of ground, comminuted and muscle meat products. Meat Science. 65(3): 959-965.

Lin, T.M., Durance, T.D. and Seaman, C.H. 1998. Characterization of vacuum microwave, air and freeze dried carrot slices. Food Research International. 31(2): 111-117.

Lin. S., Brewer, M.S. 2005. Effect of Blanching Method on the Quality Characteristics of Frozen Peas. J Food Quality. 28: 350-360.

Marra, F., Zhang, L. and Lyng, J.G. 2009. Radio frequency treatment of foods: Review of recent advances. Journal of Food Engineering. 91:497-508.

Mermelstein, N.H. 1998. Microwave and radio frequency drying. Food Technology. 52(11): 84-86.

Mitcham, E.J., Veltman, R.H., Feng, X., De Castro, E. and Johnson, J.A. 2004. Application of radio frequency treatments to control insects in in-shell walnuts. Postharvest Biology and Technology. 33:93-100.

Monzon, M., Biasi, B., Wang, S.J., Tang, J., Hallman, G. and Mitcham, E. 2004. Radio frequency heating of persimmon and guava fruit as an alternative quarantine treatment. Hortscience. 
39:879.

Monzon, M.E., Biasi, B., Mitcham, E.J., Wang, S., Tan, J. and Hallman, G.J. 2007. Effect of Radiofrequency Heating on the Quality of 'Fuyu' Persimmon Fruit as a Treatment for Control of the Mexican Fruit Fly. HORTSCIENCE. 42(1):125-129.

Moyer, J.C. and Stotz, E. 1947. The blanching of vegetables by electronics. Food Technology. 1:252-257.

Mudgett, R.E. 1989. Microwave food processing. Food Technology. 43(1): 117.

Muftugil, N. 1986. Effect of Different Types of Blanching on the Color and the Ascorbic Acid and Chlorophyll Contents of Green Beans. J Food Process Pres 10: 69-76.

Munich. S.L.K. Report No. 564, The Swedish Institute for Food and Biotechnology, Goteborg, Sweden.

Murphy, A., Morrow, R. and Besley, L. 1992. Combined radiofrequency and forcedair drying of alfalfa. Journal of Microwave Power and Electromagnetic Energy. 27(4): 223-232.

Nihan Merve Sarıkaya, Bir işyerinde elektromanyetik alan ölçümü yapılması ve sonuçlarının iş sağlığı ve güvenliği açısından değerlendirilmesi, İş sağlı̆̆ ve güvenliği uzmanlık tezi, 2014.

Ohlsson T .1987. Sterilization of foods by microwaves. International Seminar on New Trends in Aseptic Processing and Packaging of Food stuffs.

Ohlsson, T. 1993. Domestic use of microwave ovens. In: Macrae R, Robinson, RK and Sadler, MJ, editors. Encyclopaedia of food science food technology and nutrition. London: Academic Press. 2: 1232-1237.

Oliveira, MEC and Franca AS. Microwave heating of foodstuff. Journal of Food Engineering. 2002; 53: 347-359.

Orsat, V. and Raghavan, G.S. 2005. RadioFrequency Processing. Bio resource. 446-450.

Özkaya, U., Seyfi, L. and Yaldız,. E. 2018.
Analysis of Electromagnetic Radiation in Daily Life. ISAS. 3-505-509.

Patricia, C.M., Bibiana, D.Y., Jose, P.M. 2011. Evaluation of microwave technology in blanching of broccoli (Brassica oleraceae L. var Botrytis) as a substitute for conventional blanching. Procedia Food Science. 1: 426-432.

Piyasena, P., Dussault, C., Koutchma, T., Ramaswamy, H.S., Awuah, G.B., 2003. Radio frequency heating of foods: principles, applications and related properties. Food Science and Nutrition. 43 (6):587-606.

Ponne, C.T., Baysal, T., Yuksel, D. 1994. Blanching Leafy Vegetables with Electromagnetic Energy. J Food Sci. 59: 1037-1041.

Prabhanjan, D.G., Ramaswamy, H.S. and Raghavan, G.S.V. 1995. Microwave assisted convective air drying of thin layer carrots. Journal of Food Engineering. 25(2): 283-293.

Proctor, B.E. and Goldblith, S.A. 1948. Radar energy for rapid food cooking and blanching and its effect on vitamin content. Food Technology. 2:95-104.

Ptasznik, W., Zygmunt, S. and Kudra, T. 1990. Simulation of RF-assisted convective drying for seed quality broad bean. Drying Technology. 8: 977-992.

Püschner, H.A. 1996. Heating with Microwaves, Berlin, Philips Technical Library.

Ramesh, M.N., Wolf, W., Tevini, D., Bognar, A. 2002. Microwave Blanching of Vegetables. J Food Sci. 67: 390-398.

Ryynanen, S 1995. The electromagnetic properties of food materials: a review of the basic principles. Journal of Food Engineering. 26: 409-425.

Sánchez-Hernández, D., Devece, C., Catalá, J.M., Rodríguez-López, J.N., Tudela, J. 1999. Enzyme inactivation analyses for industrial blanching applications employing $2450 \mathrm{Mhz}$ monomode microwave cavities. J Microw Power Electromagn Energy. 34: 239-252.

Schirack, A.V., Sanders, T.H., Sandeep, K.P. 
2007. Effect of processing parameters on the temperature and moisture content of microwave-blanched peanuts. Journal of Food Process Engineering. 30(2):225 - 240.

Spencer, P. 1952. Means for Treating Foodstuffs. U. S. Patent 2,605,383, 605, 383.

Straumite, E., Kruma, Z., Galoburda, R., Saulite, K. 2012. Effect of Blanching on the Quality of Microwave Vacuum Dried Dill (Anethum graveolens L.). World Academy of Science, Engineering and Technology. 64: 756-762.

Tang, J., Ikediala, J.N., Wang, S., Hansen, J.D. and R.P. 2000. Cavalieri. Hightemperature-short-time thermal quarantine methods. Postharvest Biology and Technology. 21: 129-145.

Tang. J., Wang, Y. and Chan, T.V.C.T. 2005. Radio frequency heating in food processing. Novel Food Processing Technologies. 3:501-524.

Tong CH, Lentz RR, Rossen JL .1994. Dielectric Properties of Pea Puree at 915 $\mathrm{MHz}$ and $2450 \mathrm{MHz}$ as a Function of Temperature. J Food Sci. 59: 121-122.
Uemura, K., Takahashi, C., Kobayashi, I., 2011. Inactivation of Bacillus subtilis spores in soybean milk in radio-frequency flash heating. Journal of Food Engineering. 100: 622-626.

Villamiel, M., Corzo, N., Martinez-Castro, I. and Olano, A. 1996. Chemical changes during microwave treatment of milk. Food Chem. 56:385-388.

Wang, J., Luechapattanaporn, K., Wang, Y., Tang, J., 2012. "Radiofrequency heating of heterogeneous food - Meat lasagna". Journal of Food Engineering. 108:183193.

Wang, S., Tang, J., Johnson, J.A., Mitcham, E., Hansen, J.D., Cavalieri, R.P., Bower, J. and Biasi, B. 2002. Process protocols based on radio frequency energy to control field and storage pests in in-shell walnuts. Postharvest Biology Technology. 26:263-273.

Yongsawatdigul, J. and Gunasekaran, S. 1996. Microwave-vacuum drying of cranberries, part I: energy use and efficiency. Journal of Food Processing and Preservation. 20: 121-143.

\section{How to cite this article:}

Kanchan Bhatt, Devina Vaidya, Manisha Kaushal, Anil Gupta, Pooja Soni, Priyana Arya, Anjali Gautam and Chetna Sharma. 2020. Microwaves and Radiowaves: In Food Processing and Preservation. Int.J.Curr.Microbiol.App.Sci. 9(09): 118-131.

doi: https://doi.org/10.20546/ijcmas.2020.909.015 